\title{
The Research on Model Innovation of University Library Information Service under Big Data Era
}

\author{
Quan Yuan \\ Wuhan university of technology library, China
}

Keywords: Big data era, university library, information service, model innovation

\begin{abstract}
The analysis of big data realizes the high efficiency and convenience of contemporary university libraries in the management of library and information resources. In the literature management of university libraries, the use of big data theory for data mining, mass data analysis, high-dimensional data reading, reflects the advantages of big data technology, through scientific statistics and analysis of network reading and other complex data structure, which can greatly promote the scientific research and teaching work of colleges and universities and improve work efficiency. Big data technology enables university libraries to successfully cooperate with other academic research institutions in the Internet era. The use of big data technology in contemporary university libraries has become a landmark achievement in the innovative development strategy of information resources management.
\end{abstract}

\section{Introduction}

Humanity has entered the era of big data. Big data is a huge amount of data. It is large in scale and large in data collection that greatly exceeds the capabilities of the human brain and even data software tools in terms of acquisition, analysis, management, and storage. The huge data volume, rapid data flow, various data types, and the value of data are four characteristics of big data. Academician Youyi Zheng of the Chinese Academy of Sciences pointed out that the information storm brought by big data is transforming human life, work, and thinking, and has initiated a major transformation of the times. The era of big data brings development opportunities to library work. With the explosive development of data information, more and more types of library databases are available. Library readers' information needs, data mining, and internal data storage are greatly affected [1]. With the change of data volume, how to use the big data mining technology to find the information needs of users in the ocean of information, building a library-based information service model based on big data will be an important issue worthy of research and discussion.

\section{The concept of big data age digital library}

\subsection{Big Data Era}

"Time" is actually a very broad concept. It contains a very large time frame, usually referring to the collective term of time, and the big data era refers to the use of big data as the core in this period. All kinds of new inventions related to data are produced. These new things are all related to big data. The final form of data development after all things are merged is a new type of technology development model. In fact, big data has been widely used in our lives. For example, some of the relatively large-scale e-commerce platforms in China currently use big data to sell goods. They will adopt the form of data search to People often browse the web page information, through the integration of the data can analyze the individual's usual shopping preferences [1]. Therefore, through the analysis of big data applications on e-commerce websites, it is not difficult to see that more applications of big data are actually used to serve our lives. It is very beneficial to our entire life structure. This is what the big data era brings. 


\subsection{Digital library}

The library is a reading room that houses many books. The knowledge gathered here is rich. The most common type of library is the provincial and municipal libraries established in each province and city, followed by major colleges and universities. There is a great commonality among them, that is, a new type of reading unit based on physical objects, established through different types of storage, while the digital library is different from the traditional type of library. It is to store various kinds of knowledge in electronic mode and establish a digital network through stored forms. This allows us to access network data centers of various types of resources and knowledge anywhere and anytime [2]. Because today is an information society, paper books have been replaced by e-books, and more and more people are getting used to acquiring knowledge through the Internet. For example, Amazon has released digital products such as Kindle to satisfy customers.

\section{Development Status of Digital Library in Big Data Era}

\subsection{Lack of big data thinking}

Big data will be the end of human free will, and dataism will replace the previous religion and humanism and become the belief in the future. Everyone is talking about big data. In the era of DT, when we stripped off the coat of society, we return to the word "data". In general, big data has a huge impact on our lives. The author of the "Big Data Era" foresaw the benefits of big data to people's lives early in the book, along with the continuous development of information technology. In many areas, we have begun to apply big data to industrial tower exploration [2]. However, in the process of building a digital library that is not yet perfect, although the data technology of big data has also been applied, the effect is still not obvious. There seems to be a lack of a reasonable communication hub between digital libraries and big data links. In fact, the application of data in the era of big data is on the one hand, but we must also grasp the core thinking of big data, use the application model of big data, learn how to embed it into digital libraries, and let digital libraries and big data think. The most important thing is to unite closely.

\subsection{Lack of digital library management talent}

The construction of digital libraries is inseparable from the management of professionals. However, with the continuous advancement and development of science and technology, the knowledge reserve and application skills of many existing digital library librarians can no longer meet the needs of today because of the era of big data. In the background, more and more data information is flooded around our lives [2]. If there is no corresponding big data technology, it is difficult to achieve the normative construction of digital libraries. Therefore, the lack of big data talent is a major problem in the construction of digital libraries. Once management is not in place, it will cause the failure of the overall library construction.

\section{Current status of physical education teaching}

\subsection{Insufficient understanding of physical education classes by students}

In general, college students have a relatively shallow understanding of physical education classes. This is because college students are currently required to complete the heavy cultural study tasks in schools, coupled with the pressure of society and parents on their requirements for further studies, and the competition for learning is very fierce. Students only know that they are immersed in reading books and think that "participating in sports activities will waste time in learning." Therefore, the mastery of sports knowledge and sports skills is very limited, not to mention the understanding of the value and significance of physical exercise [3]. In response to this situation, I conducted a survey of students in our school in recent years, mainly to investigate students' sports the attitude of exercise, of which $24.3 \%$ is willing, $45.2 \%$ does not matter, $31.5 \%$ are unwilling. It is common for students to take a leave of absence from a physical education class or suffer from illnesses. The majority of girls are girls. The students' lack of interest in physical education directly affects the effectiveness and 
development of physical education.

\subsection{Insufficient attention to physical education from universities}

The physical education class is a relaxed business in the school. When a doll takes the lead and plays, the teacher arrangement is also more casual. In order to pursue higher education rates, many schools pay little attention to school sports. The phenomenon of heavy intelligence and light weight is very serious. Some schools have shrunk their physical education courses. The more serious is that some schools have used physical education classes for other purposes [3]. During the preparation period, physical education classes are the second class of review. Extra-curricular activities have also been reduced in time. Students can only use Sunshine Sports for an hour in 8 minutes. In addition to the one-sidedness of social understanding of sports and the impact of exam-oriented education, teachers and parents also have misunderstandings about physical education.

\subsection{Insufficient investment}

The school's contempt for physical education is compelled to understand the pressure of survival. However, some education authorities have turned a blind eye to the phenomenon of compressing physical education and extracurricular activities. The storage of sports equipment is obviously inadequate, and the lack of sports does not affect its ability to become a prestigious school [3]. Classrooms can also enjoy the unrestrained passion. National standards have made explicit regulations on physical education class time and student's time in school. There is no system restriction and guarantee. Quality education and lifetime sports are all empty talks.

\section{Innovation of university library information service model in Big Data era}

In the era of big data, the rapid development of network academic resources has greatly replaced the trend of digital libraries. In such a context, digital library construction requires big data thinking. Because the construction of a digital library can no longer be based on the original thinking of the library construction and management, big data technology and application of rapid momentum, if you cannot seize this opportunity in time may become a difficult challenge. Therefore, when we construct the framework of the entire digital library, we must clarify the context so that the construction of digital libraries meets the basic needs of users, so as to promote the development of digital libraries.

\subsection{The big data analysis application in data management and literature and knowledge modules in university libraries}

The first clear analysis object of big data analysis in the management of university libraries is massive reading data. From the perspective of data analysis, analyzing large amounts of data can be understood as the classification management of the reading object's records such as document information materials that are of interest to readers. Big data technology is suitable for university library data management, and has both temporal and spatial attributes. An important function of mass data analysis and management is to analyze and sort the identified data goals to provide the value and basis for the existence of digital book resources. Among them, the reading data in the massive data can not only reflect the importance of the document, but also reflect the utilization of the document. Literature knowledge is the interpretation and expression of concepts. Reading data is an important material for revealing the existence and relationship of knowledge [4]. A single data record does not explain the value, reliability, and cognitive level of knowledge. It only organizes and correlates the data of different records in an orderly way. Through big data analysis, it grasps the information viewed by readers, etc., and simultaneously integrates the knowledge with the literature. A comparative analysis of the common cues and differences in the key clues of reading information, an orderly interpretation of the valid information in the data, and the induction and inference of the knowledge structure and clues hidden in the data can prove the reliability and value of the knowledge [5]. 


\subsection{Cloud computing in the perspective of big data and data mining in university libraries}

The cloud computing academic cooperation program jointly conducted by Google, Washington University and Tsinghua University is actively exploring a new mode of data management in university libraries in the era of big data. Cloud computing technology based on university libraries includes four levels of data architecture, namely, infrastructure as a service (Lass for short), platform as a service (Paas), and software as a service (Saas). And data as a service (Daas), that is, network computing and reader-oriented cluster computing technology. The Internet platform has brought new opportunities for the development of software services such as university library service software (Huiwen database), such as quick feedback, online reading, borrowing and intelligentization, and reading software online upgrades [4]. "Cloud computing has enabled university library information platforms to move from the study of stand-alone software development and evolution systems to the integration of social knowledge networks and public knowledge platforms" [2]. The university library information resources use computer cloud computing technology to build a social decentralized large-scale electronic document publishing system that closely links with individual terminal readers, research institutions, and academic organizations, and serves readers of university library information resources and services. The maximization demand has risen to a closely related model. At the same time, it has also expanded the total amount of literature knowledge and methods for acquiring knowledge in university libraries [5]. For example, the resource sharing of library collections in different colleges and universities, the utilization and development of college library materials software projects, the self-adaptive evolution of library reading software upgrades, precious literature storage pools, reading terminal desktop pools, and cloud computing disaster recovery system security pools.

\subsection{Digging through reader data to provide personalized services}

With the development of computer technology and network technology, a large amount of reader information has been accumulated in the library database, including. These data information provide real and effective data resources for the study of potential user information needs. Librarians should have the ability to think big data [6]. Through the analysis and research of readers' information behavior data, they should grasp the different information needs of readers, carry out information push services and fixed-item information retrieval services, and through inter-discipline knowledge-relevance, embed information resources into subject services, promote cross-disciplinary research among different disciplines, improve the level of personalized services, and promote library management and service innovation.

\subsection{Using big data to innovate information services content}

In the era of big data, libraries should make use of the correlation and core values of big data, adjust their thinking, pay attention to new service areas, and in-depth innovative information services. The specific approach is: to strengthen readers' research and the use of interactive data for analysis. Establish user information data model, provide predictive information service products, carry out accurate knowledge related services, attach importance to the acquisition, mining, analysis and utilization of new data resources, predict possible user information needs, and mature the information collection working model and advanced the combination of mathematics models to achieve the improvement of library work efficiency; attention and integration into social networking sites such as Douban and Renren, expanding the service surface of the library, focusing on readers' preferences, collecting and sorting information resources, and improving the library's cultural life in readers Role and influence [6].

\subsection{Building big data management system}

In the big data environment, more complex data needs to be handled. Libraries must build advanced hardware facilities, build efficient distributed information networks, data storage, and data management platforms, and improve infrastructure. Develop a scientific data analysis and mining software system to improve the level of library data mining and analysis, understand readers' already 
used library services through reader-structured data, unstructured data, and semi-structured data to predict and analyze readers' future information needs, formulate scientific and reasonable development plans and service strategies, use big data to optimize service processes, and improve service decision-making [7].

\subsection{Big Data enhances the connotation of personalized service in libraries and develops personalized services}

How to use the big data technology to construct a library's new knowledge service engine will be an important part of the information technology research in the field of library and information in the next few years. The new knowledge intelligence service engine includes resources and academic search engines, resource and service recommendation engines, user and resource behavior intelligence analysis engines, user knowledge demand forecasting engines, and multi-dimensional information resource acquisition, organization, analysis, and decision engines. For example, the United States Hiptype company will use big data analysis technology to analyze e-book readers' reading habits and preferences [7]. This is the first example of the intelligence analysis engine for building knowledge service community entities (including users and resources) using big data technology in the field of library and information at home and abroad.

\section{Summary}

In summary, anyone in the early preparation phase of things must form a certain mode of thinking in the brain, and build a digital library that is different from the traditional libraries in the past. There are many basic knowledge of data storage, if only a general librarian manages the digital library, he cannot use the big data technology to serve the building of the digital library. Therefore, in the new era, it is necessary to combine the development of new technologies, learn to integrate and use big data. Serve the digital library. For the cultivation of library managers, we must not stop at the front, but must face the difficulties and transform the skills of collecting data in big data into the basic skills for the development of digital libraries so that the resources of digital libraries can be obtained. Maximize your play.

\section{References}

[1] Y.H. Yao and S.Y. Tian, System tools of the cloud computing Big Data Era, Beijing: Publishing House of Electronics Industry, 2012, vol.8, pp.7-9.

[2] Ch.J. Suo, On information resources construction of networked libraries, Library, 1999, vol.22, pp.43-45.

[3] Zh.Y. Qian, American library cooperation digital reference service, Library, 2003, vol.3, pp.37-39.

[4] W.W. Feng, The development prospects of digital library under cloud computing environment, Library and Information Service, 2012, vol.1, pp.-118-120.

[5] Sh.Y. Zhang, A preliminary study on the transformation strategy of university library information service in the era of Big Data, Journal of Agricultural Library and Information Science, 2014, vol.4, pp.173-175.

[6] F.M. Yang, Discussion on library service transformation in Big Data Environment, Library Research, 2016, vol.1, pp.48-50.

[7] C.F. Han, The impact and challenges of Big Data on Libraries, Books and Information, 2002, vol.5, pp.37-40. 